\title{
Behavior and Performance of GFRP Reinforced Concrete Columns with Various Types of Stirrups
}

\author{
Woraphot Prachasaree, ${ }^{1}$ Sitthichai Piriyakootorn, ${ }^{1}$ \\ Athawit Sangsrijun, ${ }^{2}$ and Suchart Limkatanyu ${ }^{1}$ \\ ${ }^{1}$ Department of Civil Engineering, Faculty of Engineering, Prince of Songkla University, Hat Yai, Songkhla 90112, Thailand \\ ${ }^{2}$ Program in Landscape Technology, Faculty of Agricultural Technology, Rajamangala University of Technology Thanyaburi, \\ Thanyaburi, Pathum Thani 12110, Thailand
}

Correspondence should be addressed to Woraphot Prachasaree; pworaphot@eng.psu.ac.th

Received 2 August 2015; Revised 5 September 2015; Accepted 9 September 2015

Academic Editor: João M. L. Dos Reis

Copyright (C) 2015 Woraphot Prachasaree et al. This is an open access article distributed under the Creative Commons Attribution License, which permits unrestricted use, distribution, and reproduction in any medium, provided the original work is properly cited.

Fiber reinforced polymer (FRP) composites are gaining acceptance in concrete structural applications due to their high ratio of strength/stiffness to self-weight and corrosion resistance. This study focused on the structural behavior and the performance of concrete columns internally reinforced with glass fiber reinforced plastic (GFRP) rebars. Twelve series of concrete columns with varied longitudinal reinforcement, cross section, concrete cover, and type of lateral reinforcement were tested under compression loading. The results show that the amount of GFRP longitudinal and lateral reinforcement slightly affects the column strength. The lateral reinforcement affects the confining pressure and inelastic deformation, and its contribution to the confined compressive strength increases with the GFRP reinforcement ratio. In addition, the confining pressure increases both concrete strength and deformability in the inelastic range. The confinement effectiveness coefficient varied from 3.0 to 7.0 with longitudinal reinforcement. The average deformability factors were 4.2 and 2.8 with spirals and ties, respectively. Lateral reinforcement had a more pronounced effect on deformability than on column strength.

\section{Introduction}

In general, concrete structures with conventional steel reinforcement have about 50 years of service life in an aggressive environment, such as in infrastructure highways and bridges with exposure to deicing salts, in marine structures, in waste water facilities, and in chemical treatment plants. In such conditions the corrosion of steel reinforcement leads to deterioration of the concrete structures and to loss of serviceability. This deterioration is one of the most serious problems in civil and infrastructural engineering. Such facilities incur tremendous repair costs annually. The replacement of steel with noncorroding materials, such as fiber reinforced plastics (FRPs), could be effective in alleviating these problems. The structural conditions of infrastructures would require long-term durability and a high degree of performance. In reinforced concrete columns, epoxy-coated steel rebars have been used as a corrosion resistant alternative. However, this approach has its limitations because of the costs and the delayed but eventual susceptibility to corrosion. In the past decade, studies have been published on the performance and behavior of concrete structural members internally reinforced with FRPs. Fourteen concrete beam columns internally reinforced with glass fiber reinforced plastic (GFRP) rebars were experimentally investigated under compression and bending in [1]. The results showed that the maximum capacity of GFRP reinforcing rebars could only reach $70 \%$ of their tensile strength in pure flexure and $20-30 \%$ of ultimate compressive strength under axial compression. Twelve concrete columns reinforced with aramid fiber reinforced plastic (AFRP) rebars were tested under eccentric applied tension or compression [2]. It was concluded that the analysis methods for steel reinforced concrete columns were appropriate also for concrete columns reinforced with AFRP rebars. 
Kobayashi and Fujisaki [3] studied the behavior of concrete columns with various types of longitudinal reinforcement using FRP rebars. The reinforced concrete columns were subjected to concentric loading, and the failure modes were reported as concrete crushing or compressive or tensile rupture of the FRP reinforcement. In addition, the ductile failures of columns were primarily influenced by the compressive strength of the FRP rebars. A comparative study between steel and FRP reinforced concrete columns was presented by Alsayed et al. [4]. Fifteen reinforced concrete columns with different combinations of steel and GFRP rebars were tested under concentric compression. The results showed about 10 percent strength reduction in the GFRP reinforced columns from cases with steel reinforcement. Short confined concrete cylinders with different spacings $(10,20,35$, and $50 \mathrm{~mm}$ ) of aramid spiral stirrups were studied by Leung and Burgoyne [5]. The experimental results showed that the peak load capacity of test cylinders decreased with the spiral pitch. Eleven concrete cylinders internally reinforced with CFRP rebars were experimentally investigated under eccentric loads in [6] (Sharbatdar, 2003). The average concrete core strength with smaller stirrup spacing was slightly higher than with larger stirrup spacing. In 2005, Sharma et al. [7] studied the relation between the axial load capacity of a square concrete column and the GFRP reinforcement ratio. The ductility increased with the reinforcement ratio. The axial load and bending moment interaction curves for concrete columns reinforced with FRP rebars were generated by Choo et al. [8]. The FRP reinforcement contribution in the compression zone was ignored, and it was suggested that the reinforcement ratio must be at least 0.6 percent to avoid brittle failure. The performance and behavior of concrete columns, internally reinforced with GFRP rebars and CFRP spiral warps, were studied under concentric loads by Francis and Teng [9]. The experimental results showed that the load capacity of tested columns increased insignificantly when using higher elastic modulus GFRP rebars. Also, a small increase in the core confinement, strength, and stiffness of tested columns was achieved by decreasing the pitch of spiral warps. The structural performance of square concrete columns internally reinforced with GFRP rebars was evaluated under axial compressive load in [10]. The ductility increased with the main reinforcement ratios, rapidly with small ratios but the effects were quite low for large reinforcement ratios. The compression behavior of square concrete columns reinforced with FRP rebars and hoops stirrups was investigated by Tobbi et al. [11]. The nominal column capacity could be determined by using a 65 percent reduction in the tensile strength of FRP rebars. In a recent study, twelve circular concrete columns, reinforced with GFRP rebars and spirals, were tested under concentric axial loads [12]. The experimental results indicated that the concrete columns reinforced with GFRP rebars and steel reinforced concrete columns behaved in a similar manner. The average axial load capacity contributed by longitudinal GFRP rebars was from 5 to 10 percent of the maximum load capacity. For column design purposes, the FRP contribution to compressive strength could be neglected in the axial load capacity.
Moreover, performance and behavior of FRP confined concrete have widely interested many researchers over the last two decades. The compressive and confinement behavior of both concrete and reinforced concrete-filled fiber reinforced plastic tube were investigated through experiments. The results showed that the structural performance of test specimens was improved [13]. Numerous experimental and analytical studies have been conducted to understand and model the behavior of FRP confined concrete. Eighty-eight axial stress-strain models (published between 1991 and the end of 2011) of FRP confined concrete in circular sections were comprehensively reviewed by Ozbakkaloglu et al. [14]. All developed stress-strain models can be classified into two categories as follows: the design-orientated and analysisorientated type. More than 700 experimental pieces of data of FRP confined concrete cylinders under monotonic axial compression were assessed through the previous stress-strain models. The assessment result showed that the stress-strain models developed by Lam and Teng [15] and Tamuzs et al. [16] provide the most accurate prediction of the ultimate strength and stain enhancement ratio, respectively. Recently, behavior of circular and rectangular high strength concretefilled FRP tubes was experimentally studied under axial compression $[17,18]$. The results showed that the specimen size did not significantly affect the compressive behavior of test specimens. The compressive behavior of test specimens was mainly influenced by fiber type and manufacturing method.

Many prior studies have assessed the performance and behavior of columns with GFRP rebars as longitudinal reinforcement and concrete-filled FRP tubes, as discussed above. However, at present most guidelines and standard codes of practice have no recommendations regarding FRP as longitudinal reinforcement in compression members. This might be due to the lack of rational design methodologies. The objective of this research was to experimentally evaluate the structural performance and investigate the behavior of GFRP reinforced concrete columns with various types of lateral reinforcement, to facilitate the future development of appropriate design principles.

\section{Column Specimens}

Twelve groups of concrete columns with different cross sections and reinforcement types were tested under concentric axial compressive load. For each group of concrete columns, three column specimens were cast and wet cured for 28 days before testing. The specimens were reinforced with ties, spirals or hoops, and longitudinal GFRP rebars. All specimens had the same $500 \mathrm{~mm}$ length. The height to diameter ratio was 3.3-4.0, depending on whether the column had a concrete cover or not. The concrete covers used were $15 \mathrm{~mm}$ thick. Thus, the ratio of the gross area to the concrete core area of the specimen section for both square and circular sections was equal to 1.44 . For column specimens with longitudinal reinforcement, four GFRP rebars were used in this study. The main reinforcement ratio varied from 1.42 to 2.05 (from 1.91 to 2.63) for column specimens with square (circular) section. In addition, the area of lateral 
TABLE 1: Characteristics of the test specimens.

\begin{tabular}{|c|c|c|c|c|c|c|c|c|c|}
\hline Group number & Sample label & Cross section & Reinforcement & Stirrup & Cover $(\mathrm{cm})$ & Dimension $(\mathrm{cm})$ & $\rho_{\text {frp }}(\%)$ & $\rho_{s}^{\prime}(\%)$ & $f_{c}^{\prime}(\mathrm{ksc})$ \\
\hline $\mathrm{C}-1$ & SF-sc & \multirow{4}{*}{ Square (S) } & $\mathrm{FRP}(\mathrm{F})$ & \multirow{4}{*}{ Spiral (s) } & \multirow{2}{*}{$1.25(\mathrm{c})$} & $15.0 \times 15.0$ & 1.42 & \multirow{12}{*}{1.10} & \\
\hline $\mathrm{C}-2$ & SN-sc & & - & & & $15.0 \times 15.0$ & - & & \\
\hline $\mathrm{C}-3$ & SF-sn & & FRP (F) & & \multirow{2}{*}{$-(\mathrm{n})$} & $12.5 \times 12.5$ & 2.05 & & \\
\hline $\mathrm{C}-4$ & SN-sn & & - & & & $12.5 \times 12.5$ & - & & \\
\hline C-5 & CF-sc & \multirow{4}{*}{ Circle (C) } & $\operatorname{FRP}(F)$ & \multirow{4}{*}{ Spiral (s) } & \multirow{2}{*}{$1.25(\mathrm{c})$} & $\varnothing 15.0$ & 1.91 & & \\
\hline C-6 & $\mathrm{CN}-\mathrm{sc}$ & & - & & & $\varnothing 15.0$ & - & & \\
\hline C-7 & CF-sn & & $\operatorname{FRP}(F)$ & & \multirow{2}{*}{$-(\mathrm{n})$} & $\varnothing 12.5$ & 2.63 & & \\
\hline C-8 & $\mathrm{CN}-\mathrm{sn}$ & & - & & & $\varnothing 12.5$ & - & & \\
\hline C-9 & SF-tc & \multirow{4}{*}{ Square (S) } & $\mathrm{FRP}(\mathrm{F})$ & \multirow{4}{*}{ Tied (t) } & \multirow{2}{*}{$1.25(\mathrm{c})$} & $15.0 \times 15.0$ & 1.42 & & \\
\hline $\mathrm{C}-10$ & SN-tc & & 一 & & & $15.0 \times 15.0$ & - & & \\
\hline C-11 & SF-tn & & FRP (F) & & \multirow{2}{*}{$-(\mathrm{n})$} & $12.5 \times 12.5$ & 2.05 & & \\
\hline C-12 & SN-tn & & - & & & $12.5 \times 12.5$ & - & & \\
\hline
\end{tabular}

reinforcement was 0.011 times the concrete core area. To control failure region and prevent premature failure at the end zones of the test columns, the lateral reinforcement spacing in the end zones ( one-fourth of column height) was reduced to half the specific spacing in the middle zone. The details of the column specimens are summarized in Table 1 and Figure 1. In this study, we labeled the column specimens informatively with alphanumeric codes as follows. The initial " $\mathrm{S}$ " or " $\mathrm{C}$ " distinguishes between square and circular cross sections, and the next capital letter " $F$ " or " $N$ " indicates reinforcement with GFRP rebars or lack of main reinforcement. The second group in the labels starts with "s" or " $t$," indicating spiral or tied reinforcement, and ends by indicating the concrete cover with a " $\mathrm{c}$ " or lack of it with an "n."

\section{Materials}

The concrete used in this research was a Ready-mix, normal strength and weight concrete with $100 \mathrm{~mm}$ slump, obtained from a local supplier. Conventional steel round bars with diameter $6 \mathrm{~mm}$ and grade SR24 (yield strength of $240 \mathrm{MPa}$ ) were used for lateral steel reinforcement. Different types of lateral reinforcement, namely, circular spiral, rectangular spiral, and tied stirrups, were prepared with $50 \mathrm{~mm}$ spacing in the $\sim 250 \mathrm{~mm}$ long middle zone of the column. The plain concrete columns were cast and tested after curing for 28 days. The unconfined plain concrete columns were prepared for dimensions identical with the GFRP reinforced columns that had different lateral reinforcement. Glass fiber reinforced polymer (GFRP) rods with $10 \mathrm{~mm}$ diameter were used for longitudinal reinforcement. The GFRP rebars provide excellent mechanical properties such as high tensile strength, absence of corrosion or good corrosion resistance, and light weight, in comparison to conventional steel rebars. These GFRP rebars had approximately $735 \mathrm{MPa}$ tensile strength. However, the compressive strength of FRP rebars is significantly lower than their tensile strength $[3,19]$. Due to the many different modes of failure (ACI 440.1R-06) that range from buckling of the entire rebars to local microbuckling of individual fibers, no standards exist yet for axial compression tests of FRP rebars. The anisotropy and inhomogeneity of
FRP rebar material are important factors that lead to complicated behavior under compressive loading and inaccurate test data. As reported in previous studies $[3,19]$, the compressive strength of FRP rebars must be reduced before estimating column load capacities. Deitz et al. [19] suggested a $50 \%$ reduction in the tensile strength of FRP rebars. In addition, the GFRP rebar compressive strength is 30 to 40 percent of its tensile strength, according to Kobayashi and Fujisaki [3]. It should be noted that the factor by which compressive strength is reduced depends on the fiber volume fraction, the type of polymer matrix, the manufacturing process, and the testing procedure, among other things.

\section{Experimental Test Program}

To investigate their structural performance and behavior, the concrete column specimens were tested under axial load. Cross section shape, use of concrete cover, and type of lateral reinforcement were varied to study their effects. Seven strain gages were mounted on each specimen at three positions on the column surface. To observe the reinforcement, two strain gages were attached to each surface of GFRP rebars and steel stirrups. To monitor the vertical displacement at the mid position lengthwise, linear variable differential transducers (LVDTs) with $150 \mathrm{~mm}$ gage length were used. The loads and vertical deformations were plotted for these effectively continuously recorded data. To conduct the monotonically compressive load test, the concrete column specimen was placed on a steel roller support, located on the steel base of a universal testing machine. Another steel roller support was placed on the top of the tested column. A concentrated compression load was applied to the thick steel plate over the top roller to distribute the compression load across the tested column specimen. A data acquisition system connected to all sensors as strain gages, LVDTs, and the load cell of the universal testing machine recorded the observational data. The test set-up is schematically presented in Figure 2.

\section{Experimental Results and Discussion}

The study investigated the performance and behavior of concrete columns with and without GFRP reinforcement, 

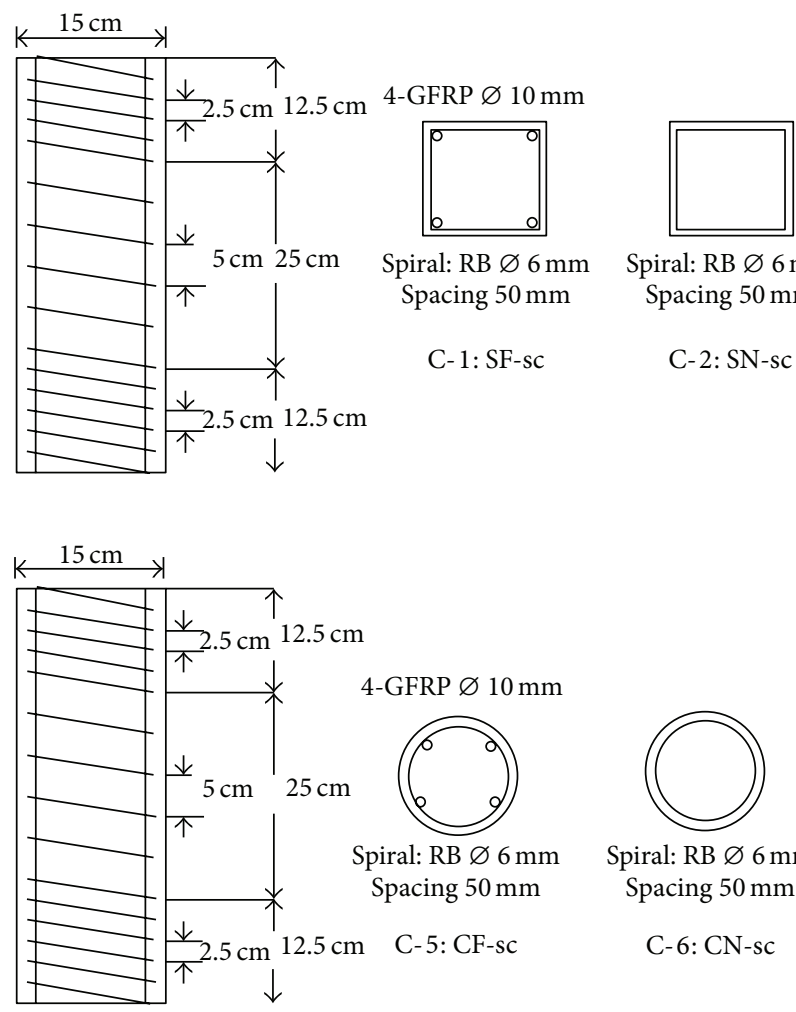

4-GFRP $\varnothing 10 \mathrm{~mm}$

Spiral: RB $\varnothing 6 \mathrm{~mm}$ Spacing $50 \mathrm{~mm}$
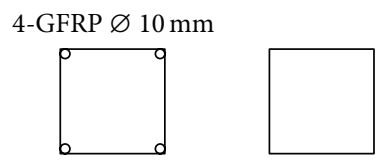

Spiral: RB $\varnothing 6 \mathrm{~mm}$ Spiral: RB $\varnothing 6 \mathrm{~mm}$ Spacing $50 \mathrm{~mm} \quad$ Spacing $50 \mathrm{~mm}$

$$
\text { C-2: SN-sc C-3: SF-sn C-4: SN-sn }
$$

Spiral: RB $\varnothing 6 \mathrm{~mm}$ Spiral: RB $\varnothing 6 \mathrm{~mm}$ Spiral: $\mathrm{RB} \varnothing 6 \mathrm{~mm}$ Spacing $50 \mathrm{~mm}$ Spacing $50 \mathrm{~mm}$ Spacing $50 \mathrm{~mm}$

$$
\text { C-6: CN-sc C-7: CF-sn C-8: CN-sn }
$$

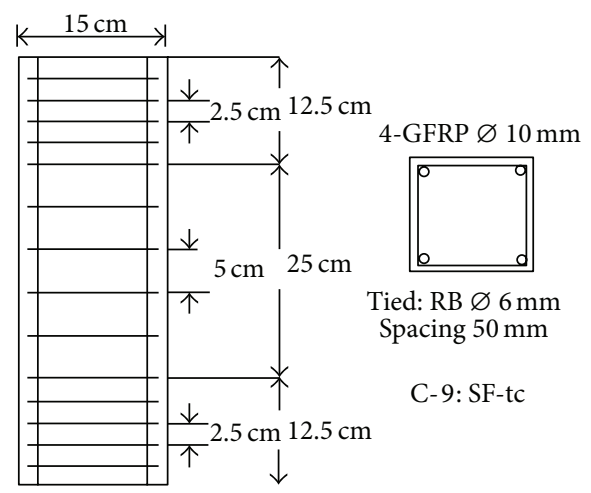

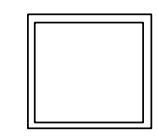

Tied: RB $\varnothing 6 \mathrm{~mm}$ Spacing $50 \mathrm{~mm}$

C-10: SN-tc
4-GFRP $\varnothing 10 \mathrm{~mm}$

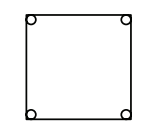

Tied: RB $\varnothing 6 \mathrm{~mm}$ Spacing $50 \mathrm{~mm}$

C-11: SF-tn

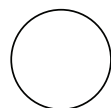

Figure 1: Geometry of the test specimens.
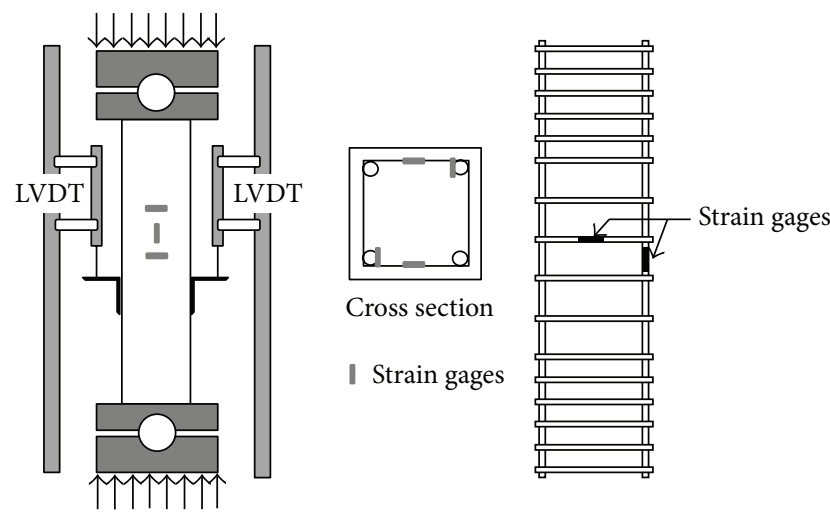

FIgURE 2: Schematic of the compression test set-up. 
TABLE 2: Experimental test results.

\begin{tabular}{|c|c|c|c|c|c|c|c|c|}
\hline \multirow{2}{*}{ Group sample } & \multirow{2}{*}{ Number } & \multirow{2}{*}{$\rho_{\text {frp }}(\%)$} & \multirow{2}{*}{ Stirrup } & \multicolumn{2}{|c|}{ @ Maximum compressive } & \multicolumn{2}{|r|}{ Avg. ratio } & \multirow{2}{*}{$\begin{array}{c}\text { @ Maximum } \\
\text { compressive } \\
\text { Column axial strain } \\
(\mathrm{mm} / \mathrm{mm})\end{array}$} \\
\hline & & & & Strength $(\mathrm{kN})$ & Stress (MPa) & $f_{c c}^{\prime} / f_{c}^{\prime}$ & $\%$ of difference & \\
\hline \multirow{3}{*}{$\begin{array}{l}\text { C-1 } \\
\text { SF-sc }\end{array}$} & 1 & \multirow{3}{*}{1.42} & \multirow{3}{*}{ Spiral (s) } & 380 & 16.9 & \multirow{3}{*}{1.643} & \multirow{6}{*}{0.218} & 0.005 \\
\hline & 2 & & & 340 & 15.1 & & & 0.004 \\
\hline & 3 & & & 390 & 17.3 & & & 0.007 \\
\hline \multirow{3}{*}{$\begin{array}{l}\mathrm{C}-2 \\
\text { SN-sc }\end{array}$} & 1 & \multirow{3}{*}{-} & \multirow{3}{*}{ Spiral (s) } & - & - & \multirow{3}{*}{1.425} & & - \\
\hline & 2 & & & 330 & 14.7 & & & 0.005 \\
\hline & 3 & & & 310 & 13.8 & & & 0.005 \\
\hline \multirow{3}{*}{$\begin{array}{l}\text { C-3 } \\
\text { SF-sn }\end{array}$} & 1 & \multirow{3}{*}{2.05} & \multirow{3}{*}{ Spiral (s) } & 360 & 23.0 & \multirow{3}{*}{2.085} & & 0.004 \\
\hline & 2 & & & 370 & 23.7 & & & 0.004 \\
\hline & 3 & & & - & - & & 0.454 & - \\
\hline \multirow{3}{*}{$\begin{array}{l}\mathrm{C}-4 \\
\text { SN-sn }\end{array}$} & 1 & \multirow{3}{*}{ - } & \multirow{3}{*}{ Spiral (s) } & 240 & 15.4 & \multirow{3}{*}{1.631} & & 0.005 \\
\hline & 2 & & & 285 & 18.2 & & & 0.006 \\
\hline & 3 & & & 285 & 18.2 & & & 0.006 \\
\hline \multirow{3}{*}{$\begin{array}{l}\text { C-5 } \\
\text { CF-sc }\end{array}$} & 1 & \multirow{3}{*}{1.91} & & 320 & 18.1 & & & 0.006 \\
\hline & 2 & & Spiral (s) & - & - & 1.892 & & - \\
\hline & 3 & & & 370 & 21.5 & & 0.429 & 0.007 \\
\hline & 1 & & & 280 & 15.8 & & & 0.003 \\
\hline 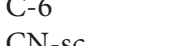 & 2 & - & Spiral (s) & 270 & 15.3 & 1.440 & & 0.006 \\
\hline $\mathrm{CN}$-sc & 3 & & & 250 & 14.1 & & & 0.007 \\
\hline & 1 & & & 310 & 25.3 & & & 0.004 \\
\hline CF-sn & 2 & 2.63 & Spiral (s) & - & - & 2.427 & & - \\
\hline & 3 & & & 320 & 26.1 & & 0.463 & 0.004 \\
\hline & 1 & & & - & - & & & - \\
\hline $\begin{array}{l}\mathrm{C}-8 \\
\mathrm{CN}-\mathrm{sn}\end{array}$ & 2 & - & Spiral (s) & 250 & 20.4 & 1.964 & & 0.003 \\
\hline CN-sn & 3 & & & 260 & 21.2 & & & 0.005 \\
\hline & 1 & & & 355 & 16.0 & & & 0.003 \\
\hline $\begin{array}{l}\text { C-9 } \\
\text { SF-tc }\end{array}$ & 2 & 1.42 & Tied (t) & 375 & 16.7 & 1.635 & & 0.004 \\
\hline & 3 & & & - & - & & 0.228 & - \\
\hline & 1 & & & 320 & 14.2 & & & 0.006 \\
\hline $\begin{array}{l}\mathrm{C}-10 \\
\text { SN-tc }\end{array}$ & 2 & - & Tied (t) & 320 & 14.2 & 1.407 & & 0.004 \\
\hline & 3 & & & 310 & 13.8 & & & 0.005 \\
\hline & 1 & & & - & - & & & - \\
\hline $\begin{array}{l}\text { C-11 } \\
\text { SF-tn }\end{array}$ & 2 & 2.05 & Tied (t) & 375 & 24.0 & 2.098 & & 0.007 \\
\hline SF-tn & 3 & & & 360 & 23.0 & & 0.552 & 0.006 \\
\hline & 1 & & & 277 & 17.7 & & & 0.003 \\
\hline $\begin{array}{l}\mathrm{C}-12 \\
\text { SN-tn }\end{array}$ & 2 & - & Tied (t) & 250 & 16.0 & 1.515 & & 0.006 \\
\hline & 3 & & & 270 & 17.2 & & & 0.007 \\
\hline
\end{tabular}

with and without concrete cover, and with various types of lateral reinforcement. The experimental results in terms of maximum load capacity and column axial strain are shown in Table 2. In general, the load-deflection relation (illustrated in Figures 3-5) of a concrete column internally reinforced with FRP rebars was quite similar to that of conventionally reinforced concrete columns. It was found that deflections increased linearly with increases of load until the concrete columns reached the maximum load capacity. Vertical cracks and crushing were found on the concrete cover that also showed spalling depending on the type of lateral reinforcement. After the concrete cover spalled off, the longitudinal reinforcements were split by lateral displacement. Then the concrete core was crushed and the longitudinal reinforcements buckled outwards between the lateral reinforcements, as shown in Figure 6. In general, the axial load capacity of a reinforced concrete column was determined both by the concrete and the longitudinal reinforcement and by their interactions. The contribution of concrete cover to the load capacity was assessed from the concrete cover strain in the transition range. From experiments as those shown in Figures 3-5 the concrete cover strain was determined from an initial spalling strain at 0.002 and the concrete cover strain at the end point of the transition range. The lateral strains (of concrete and lateral reinforcement) without concrete cover were higher than with cover when compared at a certain load, due to the confinement of the specimen core. For rectangular concrete columns reinforced with FRP, the axial load capacity with concrete covering was slightly higher than without it, by about $0.68-1.35 \%$ (C-1-C-3, C-9-C-11). However, the increase in axial load capacity of the circular columns caused by concrete covers was more significant at about $8.7 \%$. Normally, 


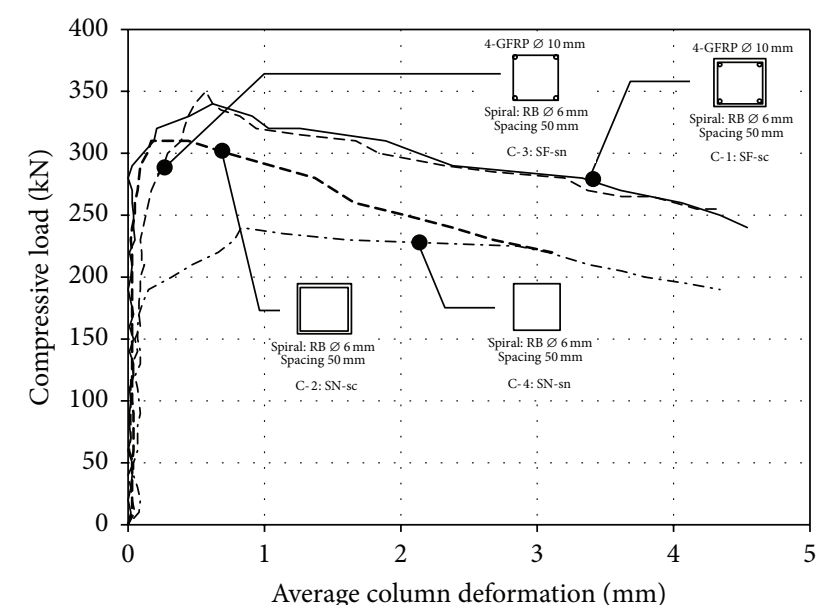

FIgURE 3: Load-deformation curves of rectangular specimens with spirals.

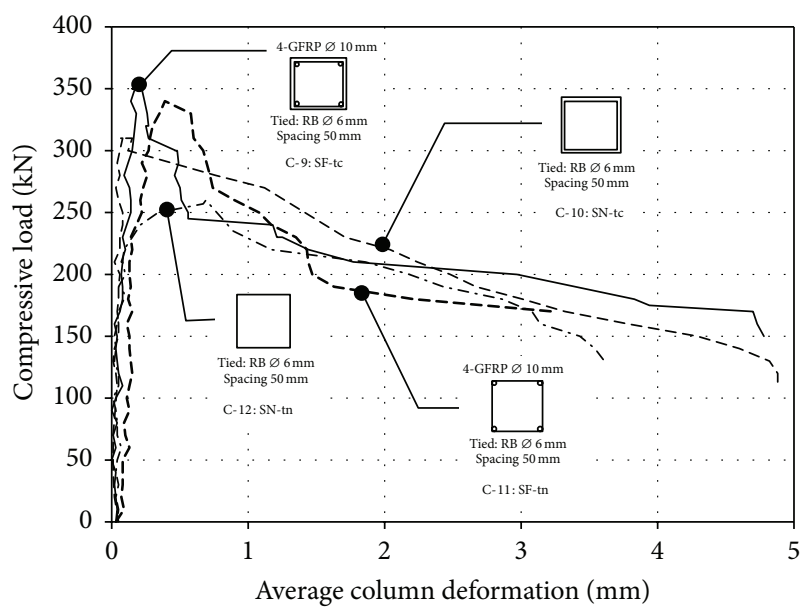

FIGURE 4: Load-deformation curves of rectangular specimens with ties.

a concrete cover affects the early effective confinement in a column, and its contribution to the column load capacity is smallish. On comparing reinforced specimens with and without GFRP reinforcement, as shown in Figures 3-5, the longitudinal GFRP reinforcement improved the loaddeformation relation as long as buckling or rupture of this reinforcement occurred. Then, the reinforcement contribution at a certain deformation can be evaluated by subtracting the capacity of plain concrete confined columns from that of GFRP reinforced concrete columns. From this approach, the GFRP reinforcement increased the axial load capacity from $13 \%$ to $36 \%$. For a rectangular cross section, the axial load capacity increase attributed to FRP with concrete covers (C-1-C-2, C-9-10) was lower by about half on comparing to cases without concrete cover (C-3-C-4, C-11-C-12). Also, the strain of GFRP related to its contribution to the load capacity. The GFRP strains with concrete cover were smaller than without cover, by about half. In addition, the axial load capacity increases of the circular columns (C-5-C-6, C-7C-8) were approximately $26.5 \%$, and the longitudinal strain

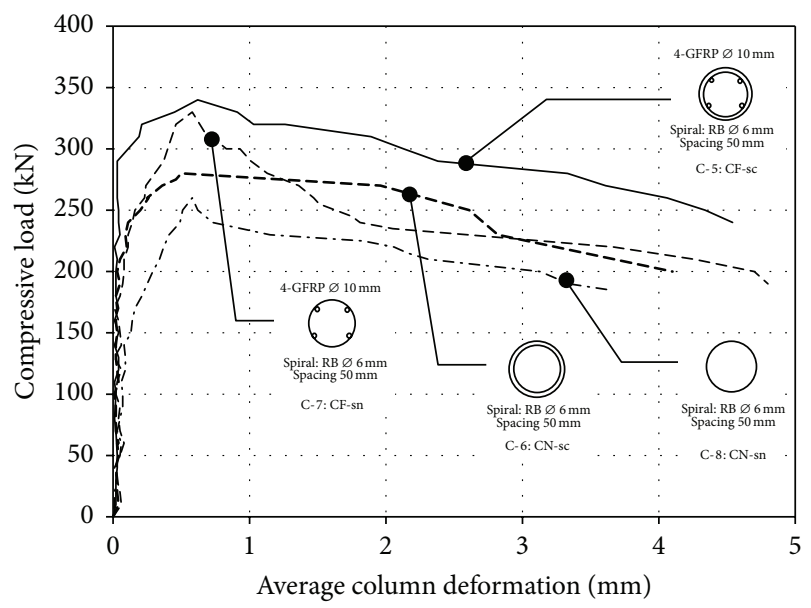

FIGURE 5: Load-deformation curves of circular specimens.

of GFRP reinforcement ranged from 0.015 to 0.02 at the maximum column capacity, as shown in Figure 7. However, the contribution of GFRP rebars under compression loading was much lower than under tension, in accordance with prior studies $[3,19]$. In addition, the effect of longitudinal reinforcement on the concrete confinement is presented in terms of ratio $f_{c c}^{\prime} / f_{c}^{\prime}$. The difference of maximum compressive strength $\left(f_{c c}^{\prime}\right)$ to the unconfined compressive strength $\left(f_{c c}^{\prime}\right)$ ratio is obtained from subtraction of this ratio between specimens with and without longitudinal reinforcement. From experimental results, the contribution to the confined compressive strength of specimens increases with an increase of GFRP reinforcement ratio as shown in Figure 8. The lateral reinforcement creates a confining pressure curing the deformation of a specimen. This confining pressure increases both strength and inelastic range of deformations. The experimental results in Figure 9 indicate no differences in the maximum load capacity between the various types of lateral reinforcement, while differences were found in the descending region of load-deformation response. It should be noted that the maximum load capacity is not reached with intact concrete cover. At maximal load the concrete cover may spall off, which reduces the load capacity. After the maximum load, a sudden drop in the load capacity occurred in specimens with ties (both with and without concrete cover). The spiral lateral reinforcement proved to be the most effective in terms of confining pressure and inelastic deformation. The effect of the lateral reinforcement on deformability was more pronounced than on the maximum load capacity, in GFRP reinforced concrete columns.

To evaluate the confinement effectiveness of GFRP reinforced concrete columns, the basic approach from conventionally reinforced concrete was used. In general, the maximum confined strength was subtracted by the unconfined strength of test specimens. The ratio between the resultant and the confined pressure provided by the lateral reinforcement defines the coefficient of confinement effectiveness. The confined pressure determined from the yielding of lateral reinforcement depends on lateral reinforcement spacing, concrete core dimension, area of lateral reinforcement, and 

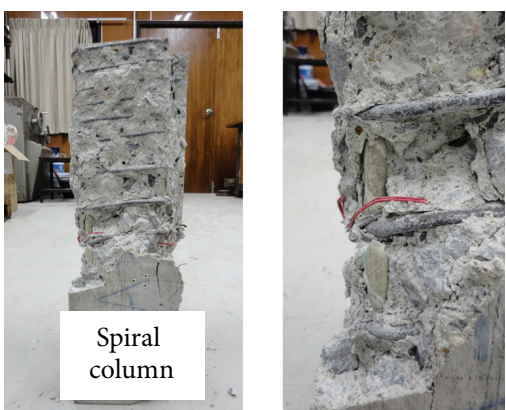

Column: SF-sc
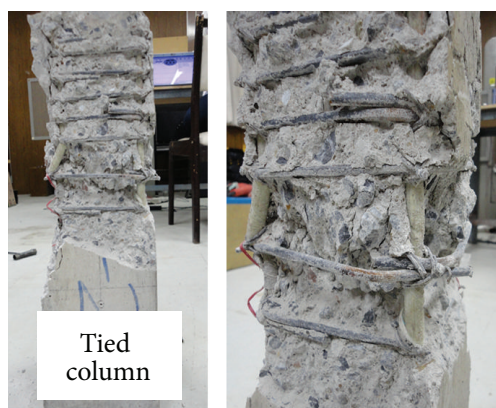

Column: SF-tc

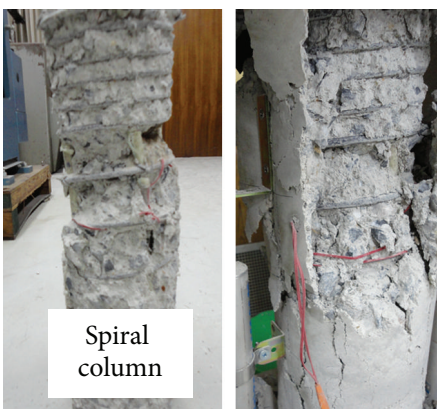

Column: $\mathrm{CF}-\mathrm{sc}$

FIGURE 6: Failure modes of GFRP columns.

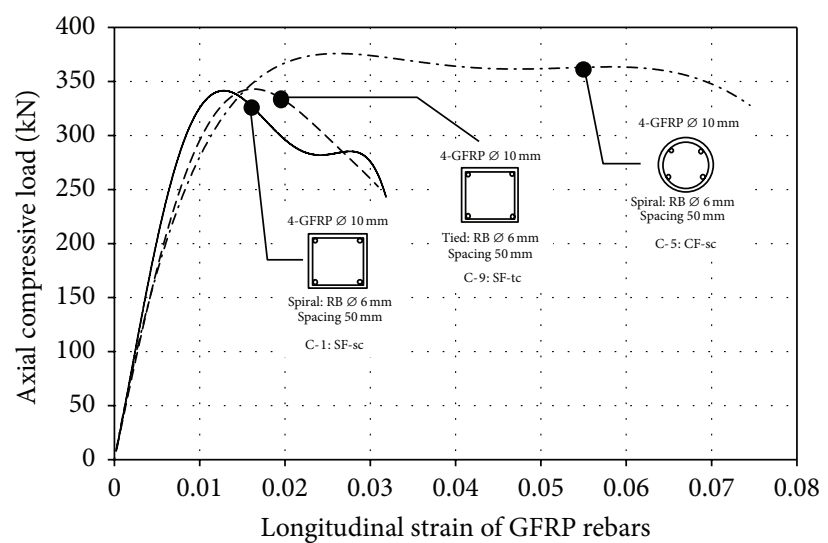

(a) Specimens with concrete cover

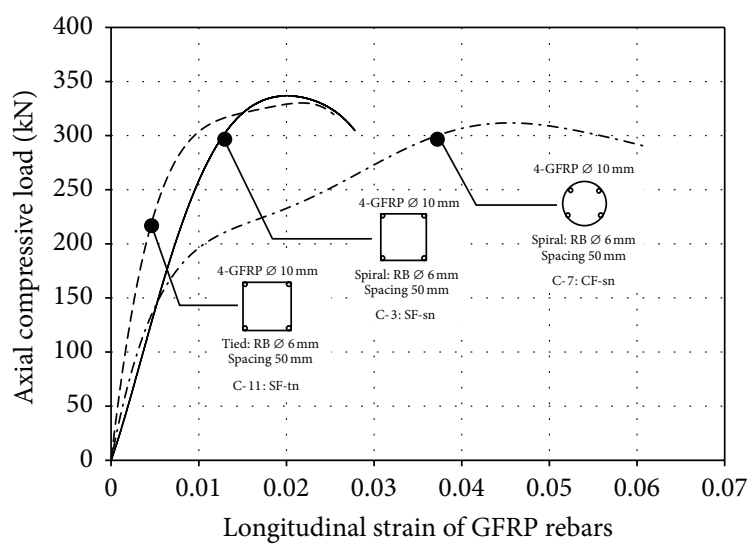

(b) Specimens without concrete cover

FIGURE 7: Load-strain curves of GFRP rebars.

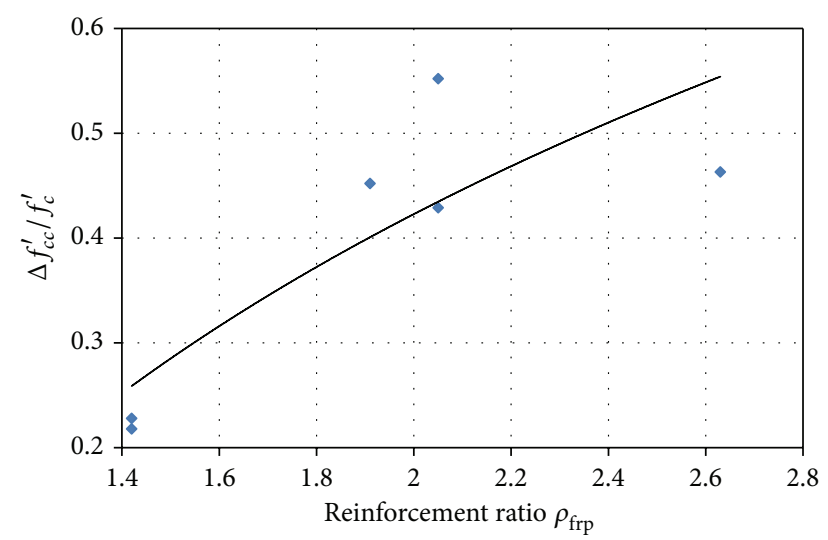

Figure 8: Relation between the difference in $f_{c c}^{\prime} / f_{c}^{\prime}$ and reinforcement ratio.

so forth. It was found that the confinement effectiveness coefficient varied from 3.0 to 7.0 for specimens with longitudinal reinforcement. The higher confinement effectiveness coefficient implied that the confined pressure is low and the unconfined concrete strength may be high. From experimental results, the specimens without concrete cover provided higher confinement effectiveness coefficients than those with

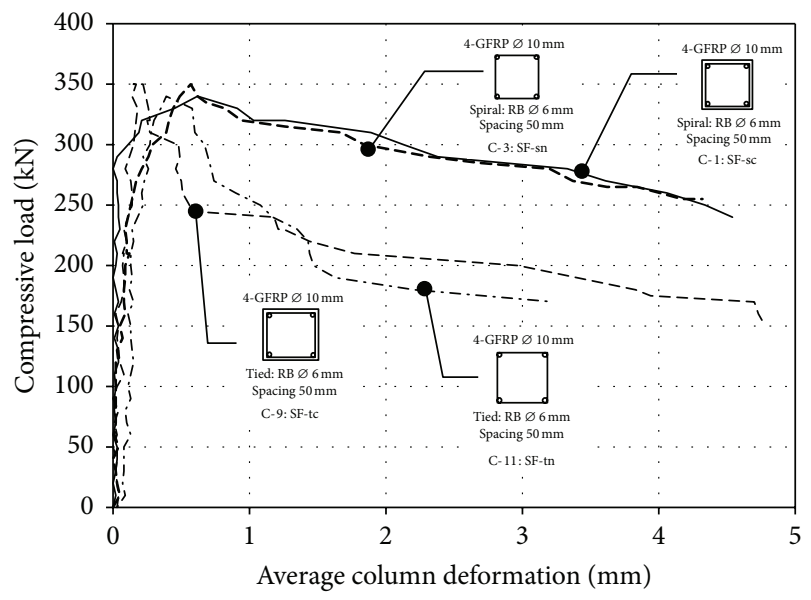

FIGURE 9: Comparison of load-strain curves with various types of lateral reinforcement.

concrete cover. This may be due to severe effects of early shrinkage and Poisson's ratio in cases without concrete cover, which delay confinement effects during specimen loading. The confinement will not be effective until large lateral deformations. 
To establish relative performance of test specimens with the stress-strain models developed in recent studies $[13,15$, $20,21]$, the strength results of test specimens with circular cross section (C-6: CN-sc) were compared with the predicted strength results. The stress-strain models of FRP confined concrete with circular sections were considered as follows:

Park et al. [13]:

$$
\frac{f_{c c}^{\prime}}{f_{c o}^{\prime}}=0.7+3.7\left(\frac{f_{l u, a}}{f_{c o}^{\prime}}\right),
$$

Lam and Teng [15]:

$$
\frac{f_{c c}^{\prime}}{f_{c o}^{\prime}}=1+3.3\left(\frac{f_{l u, a}}{f_{c o}^{\prime}}\right),
$$

Wu and Wang [20]:

$$
\frac{f_{c c}^{\prime}}{f_{c o}^{\prime}}=1+2.23\left(\frac{f_{l u}}{f_{c o}^{\prime}}\right)^{0.96},
$$

and Realfonso and Napoli [21]:

$$
\frac{f_{c c}^{\prime}}{f_{c o}^{\prime}}=1+3.57\left(\frac{f_{l u, a}}{f_{c o}^{\prime}}\right) \text {, }
$$

where $f_{c c}^{\prime}$ is maximum axial compressive stress of FRP confined concrete, $f_{c o}^{\prime}$ is maximum axial compressive stress of unconfined concrete, $f_{l u}$ is nominal lateral confining pressure at ultimate, and $f_{l u, a}$ is actual lateral confining pressure at ultimate.

The predicted compressive strength obtained from the stress and strain models (Equations (1) to (4)) is equal to $291 \mathrm{kN}, 291 \mathrm{kN}, 272 \mathrm{kN}$, and $351 \mathrm{kN}$, respectively. Based on this study, the predicted stress and strain models provide higher strength results than the average experimental results $(267 \mathrm{kN})$. The percentage difference between the predicted models and experimental results ranged from $9 \%$ to $31 \%$. The most accurate prediction of ultimate strength can be obtained from using the stress and strain model by Lam and Teng [15] and Park et al. [13] with 9 percent difference. The findings on the strength comparison between the experimental data and predicted models are in agreement with the previous study [14]. In general, the postelastic behavior of conventional reinforced concrete members is indicated by ductility factor. The ductility of steel reinforced concrete members can be defined as the ratio of displacement or deformation at ultimate point to the corresponding values at yielding point of the steel reinforcement. However, the behavior of FRP reinforcement is quite different from that of steel, particularly under compression loading. Thus, the postelastic behavior is more appropriately characterized by energy absorption than by ductility factor. In this study, the deformability factor was defined as the ratio of energy absorption (area under load and deformation curve) at the ultimate point to the energy absorption at the limiting deformation in the ascending part of load versus deformation. The ultimate point was defined as the postelastic point at 85 percent of maximum load capacity in the descending part. The limiting deformation point was defined as the deformation point at the maximum load capacity in the ascending part. From experimental results, the average deformability factors were 4.2 and 2.8 with spirals and ties, respectively.

\section{Conclusions}

Glass fiber reinforced plastic (GFRP) was used to reinforce concrete columns that were experimentally investigated under compression loading to assess structural behavior and performance. Specimens were prepared with varied longitudinal reinforcement, concrete cover, and lateral reinforcement. Based on this study, the amount of GFRP longitudinal and lateral reinforcement slightly affected the column strengths. While different types of lateral enforcement had little difference in strength, the spiral lateral reinforcement was the most effective in terms of the confining pressure and the inelastic deformation. The effect of the lateral reinforcement on deformability is more influenced than that on the column strength. The contribution to the confined compressive strength increased with the GFRP reinforcement ratio. The concrete cover mainly affected early confinement effects, not maximum load capacity or late stage deformation.

\section{Conflict of Interests}

The authors declare that there is no conflict of interests regarding the publication of this paper.

\section{Acknowledgments}

The authors would like to acknowledge Associate Professor Seppo Karrila, Ph.D., and Research and Development Office (RDO), Prince of Songkla University, for technical comments and corrections. This study was partially supported by Structural Engineering and Applied Mechanics (STREAM) Research Group under Grant ENG-51-2-7-11-022-S, Department of Civil Engineering, Faculty of Engineering, Prince of Songkla University, Hat Yai, Songkhla, Thailand.

\section{References}

[1] N. S. Paramananthan, Investigation of the behavior of concrete columns reinforced with fiber reinforced plastic rebars [M.S. thesis], Lamar University, Beaumont, Tex, USA, 1993.

[2] N. Kawaguchi, "Ultimate strength and deformation characteristics of concrete members reinforced with AFRP rods under combined axial tension or compression and bending," in Proceedings of the Interanational Symposium on Fiber Reinforced Plastic Reinforcement for Concrete Structures, Special Publication 138, pp. 671-684, 1993.

[3] K. Kobayashi and T. Fujisaki, "Compressive behavior of FRP reinforcement in non-prestressed concrete members," in NonMetallic (FRP) Reinforcement for Concrete Structures: Proceedings of the Second International RILEM, CRC Press, 1995.

[4] S. H. Alsayed, Y. A. Al-Salloum, T. H. Almusallam, and M. A. Amjad, "Concrete columns reinforced by glass fibre reinforced plastic rods," International Concrete Abstracts Portal, vol. 188, pp. 103-112, 1999. 
[5] H. Y. Leung and C. J. Burgoyne, "Compressive behavior of concrete confined by aramid fibre spirals," in Proceedings of the International Conference on Structural Engineering Mechanics and Computation, pp. 1357-1346, Cape Town, South Africa, June 2001.

[6] M. K. Sharbatdar, Concrete columns and beams reinforced with FRP bars and grids under monotonic and reversed cyclic loading [Ph.D. thesis], University of Ottawa, Ottawa, Canada, 2003.

[7] U. K. Sharma, P. Bhargava, and S. K. Kaushik, "Behavior of confined high strength concrete columns under axial compression," Journal of Advanced Concrete Technology, vol. 3, no. 2, pp. 267281, 2005.

[8] C. C. Choo, I. E. Harik, and H. Gesund, "Strength of rectangular concrete columns reinforced with fiber-reinforced polymer bars," ACI Structural Journal, vol. 103, no. 3, pp. 452-459, 2006.

[9] M. Francis and B. Teng, "Strength of short concrete columns reinforced with high modulus glass fibre reinforced polymer bars," in Proceedings of the 2nd International Structures Specialty Conference, pp. 45.1-45.8, Winnipeg, Canada, June 2010.

[10] E. M. Lotfy, "Behavior of reinforced concrete short columns with fiber reinforced polymers bars," International Journal of Civil and Structural Engineering, vol. 1, no. 3, pp. 545-557, 2010.

[11] H. Tobbi, A. S. Farghaly, and B. Benmokrane, "Concrete columns reinforced longitudinally and transversally with glass fiber-reinforced polymer bars," ACI Structural Journal, vol. 109, no. 4, pp. 1-8, 2012.

[12] M. Z. Afifi, H. M. Mohamed, and B. Benmokrane, "Axial capacity of circular concrete columns reinforced with GFRP bars and spirals," Journal of Composites for Construction, vol. 18, no. 1, pp. 363-366, 2014.

[13] J.-H. Park, B.-W. Jo, S.-J. Yoon, and S.-K. Park, "Experimental investigation on the structural behavior of concrete filled FRP tubes with/without steel re-bar," KSCE Journal of Civil Engineering, vol. 15, no. 2, pp. 337-345, 2011.

[14] T. Ozbakkaloglu, J. C. Lim, and T. Vincent, "FRP-confined concrete in circular sections: review and assessment of stressstrain models," Engineering Structures, vol. 49, pp. 1068-1088, 2013.

[15] L. Lam and J. G. Teng, "Design-oriented stress-strain model for FRP-confined concrete," Construction and Building Materials, vol. 17, no. 6-7, pp. 471-489, 2003.

[16] V. Tamuzs, R. Tepfers, E. Zile, and O. Ladnova, "Behavior of concrete cylinders confined by a carbon composite 3 . Deformability and the ultimate axial strain," Mechanics of Composite Materials, vol. 42, no. 4, pp. 303-314, 2006.

[17] T. Ozbakkaloglu, "Axial compressive behavior of square and rectangular high-strength concrete filled FRP tubes," Journal of Composites for Construction, vol. 17, no. 1, pp. 151-161, 2013.

[18] T. Ozbakkaloglu and T. Vincent, "Axial compressive behavior of circular high-strength concrete-filled FRP tubes," Journal of Composites for Construction, vol. 18, no. 2, Article ID 04013037, 2014.

[19] D. H. Deitz, I. E. Harik, and H. Gesund, "Physical properties of glass fiber reinforced polymer rebars in compression," Journal of Composites for Construction, vol. 7, no. 4, pp. 363-366, 2003.

[20] Y.-F. Wu and L.-M. Wang, "Unified strength model for square and circular concrete columns confined by external jacket," Journal of Structural Engineering, vol. 135, no. 3, pp. 253-261, 2009.

[21] R. Realfonzo and A. Napoli, "Concrete confined by FRP systems: confinement efficiency and design strength models," Composites Part B: Engineering, vol. 42, no. 4, pp. 736-755, 2011. 

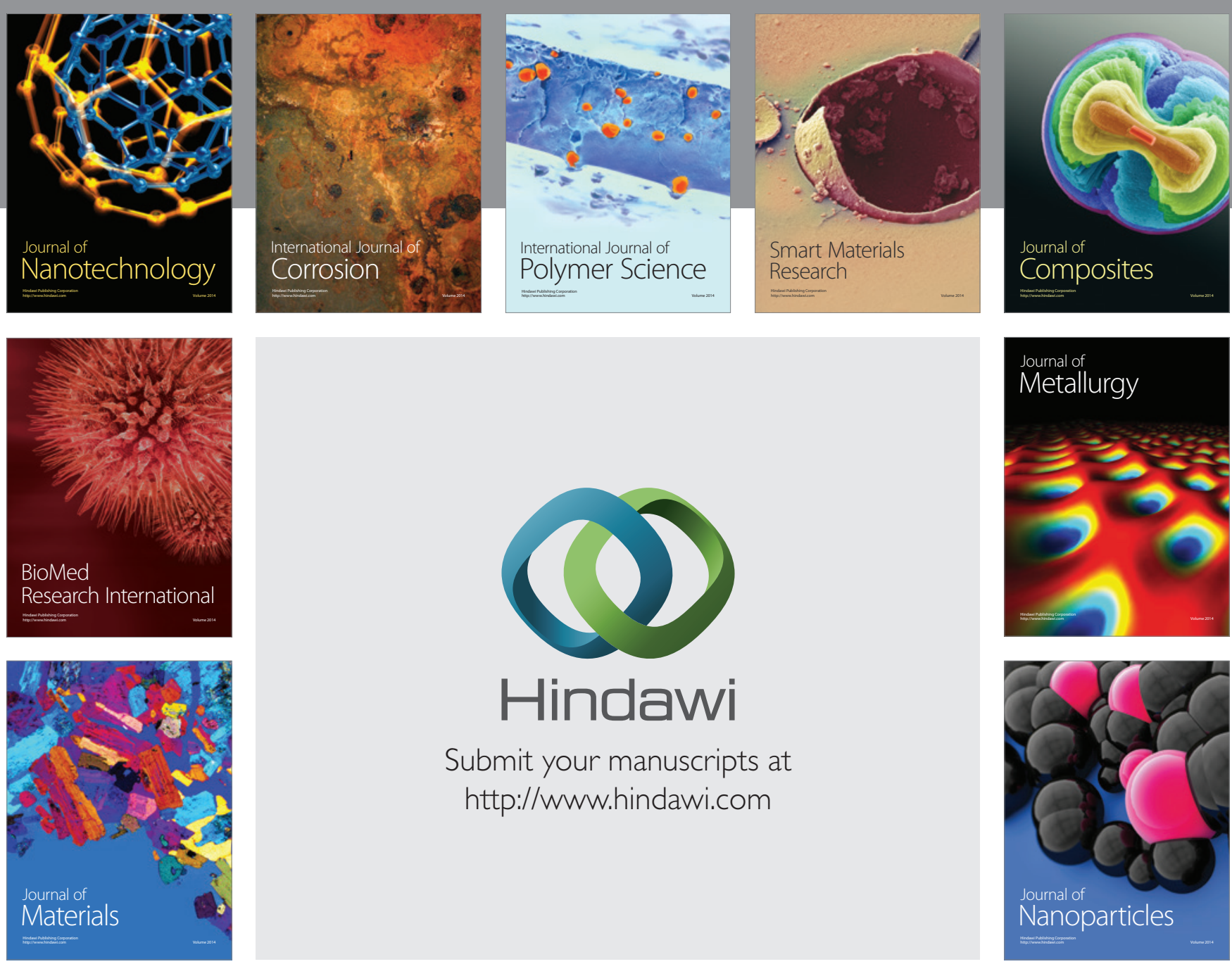

Submit your manuscripts at http://www.hindawi.com
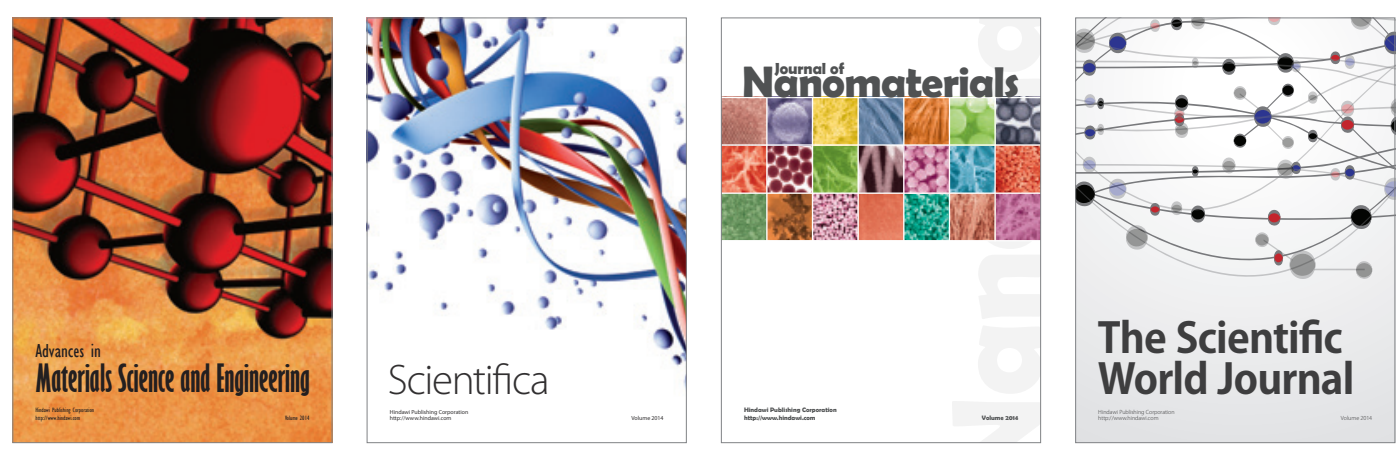

\section{The Scientific World Journal}
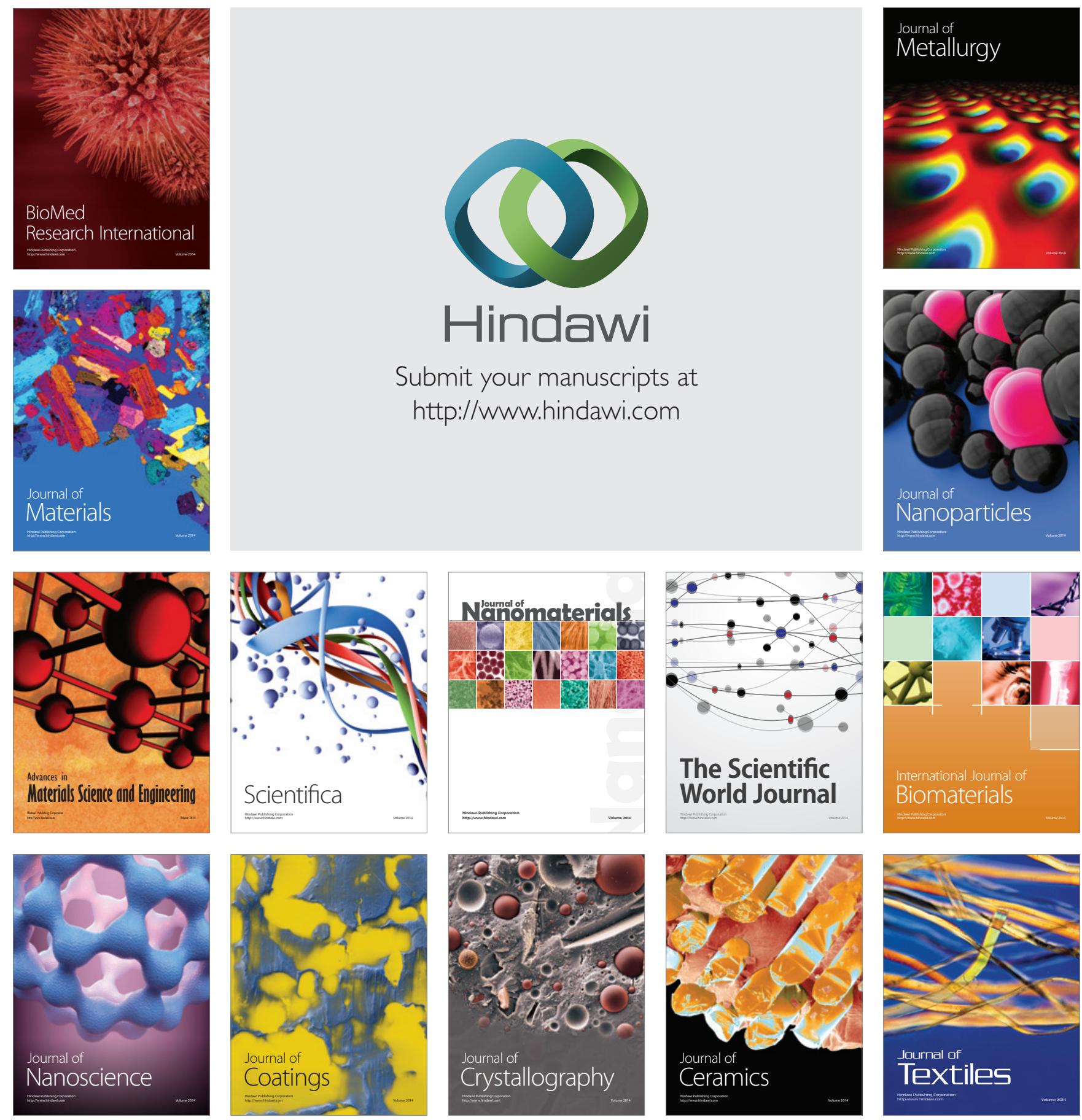